First publ. in: Freshwater Biology 54 (2009), 11, pp. 2401-2417

APPLIED ISSUES

\title{
Subfossil Cladocera in relation to contemporary environmental variables in 54 Pan-European lakes
}

\author{
RIKKE BJERRING ${ }^{*}{ }^{\dagger}$, ELOY BECARES $\ddagger$, STEVEN DECLERCK ${ }^{\S}$, ELISABETH M. GROSS \\ LARS-ANDERS HANSSON**, TIMO KAIRESALO ${ }^{+\dagger}$, MIRVA NYKÄNEN $^{+\dagger}$, ANNA HALKIEWICZ $^{\ddagger \ddagger}$, \\ RYSZARD KORNIJÓW ${ }^{\ddagger}$, JOSÉ M. CONDE-PORCUNA $\$$, MILTIADIS SEFERLIS ${ }^{\text {\% }}$, TIINA \\ NÕGES***, BRIAN MOSS ${ }^{+++}$, SUSANNE LILDAL AMSINCK*, BENT VAD ODGAARD ${ }^{\ddagger \ddagger \ddagger}$ \\ AND ERIK JEPPESEN ${ }^{*}+$ \\ *Department of Freshwater Ecology, National Environmental Research Institute, University of Aarhus, Silkeborg, \\ Denmark \\ tDepartment of Plant Biology, University of Aarhus, Aarhus C, Denmark \\ $\ddagger$ Environmental Institute, University of León, Leon, Spain \\ §Laboratory of Aquatic Ecology, Katholieke Universiteit Leuven, Leuven, Belgium \\ -Fachbereich Biologie, Limnologisches Institut, University of Konstanz, Konstanz, Germany \\ **Department of Limnology, University of Lund, Lund, Sweden \\ ++ Department of Ecological E Environmental Sciences, University of Helsinki, Lahti, Finland \\ 抽epartment of Hydrobiology, University of Life Sciences in Lublin, Lublin, Poland \\ §§Institute of Water Research, University of Granada, Granada, Spain \\ TThe Greek Biotope/Wetland Centre, Thessaloniki-Mihaniona, Thermi, Greece \\ ***Estonian University of Life Sciences, Institute of Environmental and Agricultural Sciences, Centre for Limnology, \\ Rannu, Tartu Country, Estonia \\ +十+School of Biological Sciences, University of Liverpool, Liverpool, UK \\ 怙Department of Earth Sciences, University of Aarhus, Aarhus C, Denmark
}

\begin{abstract}
SUMMARY
1. Changes in cladoceran subfossils in the surface sediments of 54 shallow lakes were studied along a European latitude gradient $\left(36-68^{\circ} \mathrm{N}\right)$. Multivariate methods, such as regression trees and ordination, were applied to explore the relationships between cladoceran taxa distribution and contemporary environmental variables, with special focus on the impact of climate.

2. Multivariate regression tree analysis showed distinct differences in cladoceran community structure and lake characteristics along the latitude gradient, identifying three groups: (i) northern lakes characterised by low annual mean temperature, conductivity, nutrient concentrations and fish abundance, (ii) southern, macrophyte rich, warm water lakes with high conductivity and high fish abundance and (iii) Mid-European lakes at intermediate latitudes with intermediate conductivities, trophic state and temperatures. 3. Large-sized, pelagic species dominated a group of seven northern lakes with low conductivity, where acid-tolerant species were also occasionally abundant. Small-sized, benthic-associated species dominated a group of five warm water lakes with high conductivity. Cladoceran communities generally showed low species-specific preferences for habitat and environmental conditions in the Mid-European group of lakes. Taxon
\end{abstract}

Correspondence: Rikke Bjerring, Department of Freshwater Ecology, National Environmental Research Institute, University of Aarhus, Vejlsøvej 25, 8600 Silkeborg, Denmark and Erik Jeppesen, also at Department of Plant Biology, Ole Worms Allé, Building 135, 8000 Aarhus C, Denmark. E-mail: rbh@dmu.dk, ej@dmu.dk 
richness was low in the southern-most, high-conductivity lakes as well as in the two northern-most sub-arctic lakes.

4. The proportion of cladoceran resting eggs relative to body shields was high in the northern lakes, and linearly (negatively) related to both temperature and $\mathrm{Chl} a$, indicating that both cold climate (short growing season) and low food availability induce high ephippia production.

5. Latitude and, implicitly, temperature were strongly correlated with conductivity and nutrient concentrations, highlighting the difficulties of disentangling a direct climate signal from indirect effects of climate, such as changes in fish community structure and humanrelated impacts, when a latitude gradient is used as a climate proxy. Future studies should focus on the interrelationships between latitude and gradients in nutrient concentration and conductivity.

Keywords: canonical correspondence analysis, ephippia, multivariate regression analysis, species richness, zooplankton structure

\section{Introduction}

In recent years, the impact of climate on ecosystems has received increasing attention due to the relatively rapid increase in global warming (IPCC, 2007). Many freshwater bodies are used for drinking water supply and irrigation, and in the future the demand for water resources is expected to increase, resulting in the risk of eutrophication, salinisation and loss of species in freshwater ecosystems (IPCC, 2007). Better knowledge of the complex effects of global warming on freshwater ecosystems is therefore urgently needed.

Lake sediments contain a natural archive of remains of various organisms and therefore offer an excellent potential for studying the impact of climate on lake ecosystems (Battarbee, 2000). In addition, this archive serves as an accurate and cost-effective tool for the assessment of species richness and community structure, integrating spatial and temporal community heterogeneity (Jeppesen et al., 2003; Brendonck \& De Meester, 2003; Vandekerkhove et al., 2005a,b). Cladoceran subfossils have been used in a number of studies to assess anthropogenic impacts on lake ecosystems, including climate-driven effects (Amsinck, Jeppesen \& Verschuren, 2007). For example, temperature transfer functions have been developed using cladoceran subfossils (Lotter et al., 1997; Korhola, 1999; Duigan \& Birks, 2000) as a direct palaeo-temperature indicator. Likewise, the ephippia to carapace ratio of Bosmina (Jeppesen et al., 2003) and chydorids (SarmajaKorjonen, 2004) may be a useful indicator of lake temperature.
Climate affects salinity and changes in salinity can be tracked directly by zooplankton using salinity transfer functions (e.g. Bos, Cumming \& Smol, 1999). Consequently, the cascading effects of changed salinity on lake ecosystems can be traced through changes in the cladoceran species composition and community structure (Verschuren et al., 2000; Amsinck, Jeppesen \& Ryves, 2003). Increasing temperature is also likely to influence the primary production of the lakes as well as the top-down control of fish (Jeppesen et al., 2005, 2007; Smol et al., 2005). Changes in lake production and trophic state also lead to changes in cladoceran community composition and in the accumulation of cladoceran subfossils (Korhola et al., 2002; Manca et al., 2007). The expected changes in fish predation pressure (Gyllström et al., 2005; Jeppesen et al., 2007) can be traced through cladoceran-based transfer functions of fish abundance (Jeppesen, Madsen \& Jensen, 1996; Amsinck, Jeppesen \& Landkildehus, 2005), as well as by the size (dorsal length) of Daphnia ephippia (Verschuren \& Marnell, 1997; Jeppesen et al., 2002) and the contribution of Daphnia ephippia to the total sum of Daphnia and Bosmina ephippia (Leavitt et al., 1994; Jeppesen et al., 2003).

Here we analysed cladoceran subfossils from surficial sediments of 54 intensively studied shallow European lakes covering a wide range in latitude (36$68^{\circ} \mathrm{N}$ ), and thus including broad gradients in climate $\left(15{ }^{\circ} \mathrm{C}\right.$ difference in mean monthly temperature of the warmest month) and nutrient concentration (e.g. total phosphorous: $6-470 \mu \mathrm{g} \mathrm{L}^{-1}$ ). Our overall aim was to identify the key environmental factors, primarily 
climate factors, structuring the cladoceran community composition, taxon richness, resting egg (ephippia) production and body size structure along the northsouth transect. We expected cladoceran community structure to be dominated by few smaller, predationresistant taxa due to increasing plankti-benthivorous fish predation with increasing temperature (Dumont, 1994; Fernando, 1994; Gyllström et al., 2005). The number of salinity resistant taxa was expected to increase and taxon richness to decrease with increased conductivity, especially in the southern-most lakes (Beklioglu et al., 2007; Declerck et al., 2005; Vandekerkhove et al., 2005a). Finally, the ephippia to body shield ratio was hypothesised to decline with decreasing latitude due to a longer growing season and thus a limited need for producing overwintering resting stages (Jeppesen et al., 2003).

\section{Methods}

\section{Study sites}

The study was based on a subset of shallow inland lakes included in various EU projects: ECOFRAME (44 European lakes), BIOMAN (six south Spanish lakes) and the EUROLIMPACS (four Greek lakes), for which information on relevant environmental variables was also available. Lake surface sediment samples were taken and environmental variables measured in 2000 (ECOFRAME: one sediment sample taken in 2003), 2000 or 2001 (BIOMAN) and 2005 (EUROLIMPACS). The 54 study lakes were located in 11 ecoregions in nine European countries (Fig. 1): Sweden (northern SN, southern SS), Finland (FIN), Estonia (EST), Poland (PL), Denmark (DK), United Kingdom (UK), Germany (D), Greece (G) and Spain (northern EN, southern ES). The lakes covered broad north-south and east-west gradients across Europe, with latitudes ranging from $36^{\circ} \mathrm{N}$ to $68^{\circ} \mathrm{N}$ and longitudes from $7^{\circ} \mathrm{W}$ to $27^{\circ} \mathrm{E}$ (Fig. 1). Mean annual air temperatures ranged from -3 to $16{ }^{\circ} \mathrm{C}$ (Table 1). In each ecoregion four to six lakes were selected to cover a eutrophication gradient (see Moss et al., 2003 and Table 1).

\section{Sampling and laboratory procedure}

Surface sediment samples (top 0-3 cm, representing the last c. 2-10 years) were taken from the deepest part of the lake using a Kajak sediment corer. Approximately $5 \mathrm{~g}$ (wet weight) of homogenised surface lake sediment was heated in $50 \mathrm{~mL}$ of $10 \%$
Fig. 1 Geographical location of the 54 European study lakes. Capital letters denote country, suffix $\mathrm{S}$ = southern, $\mathrm{N}=$ northern. Numbers of study lakes are given in brackets.

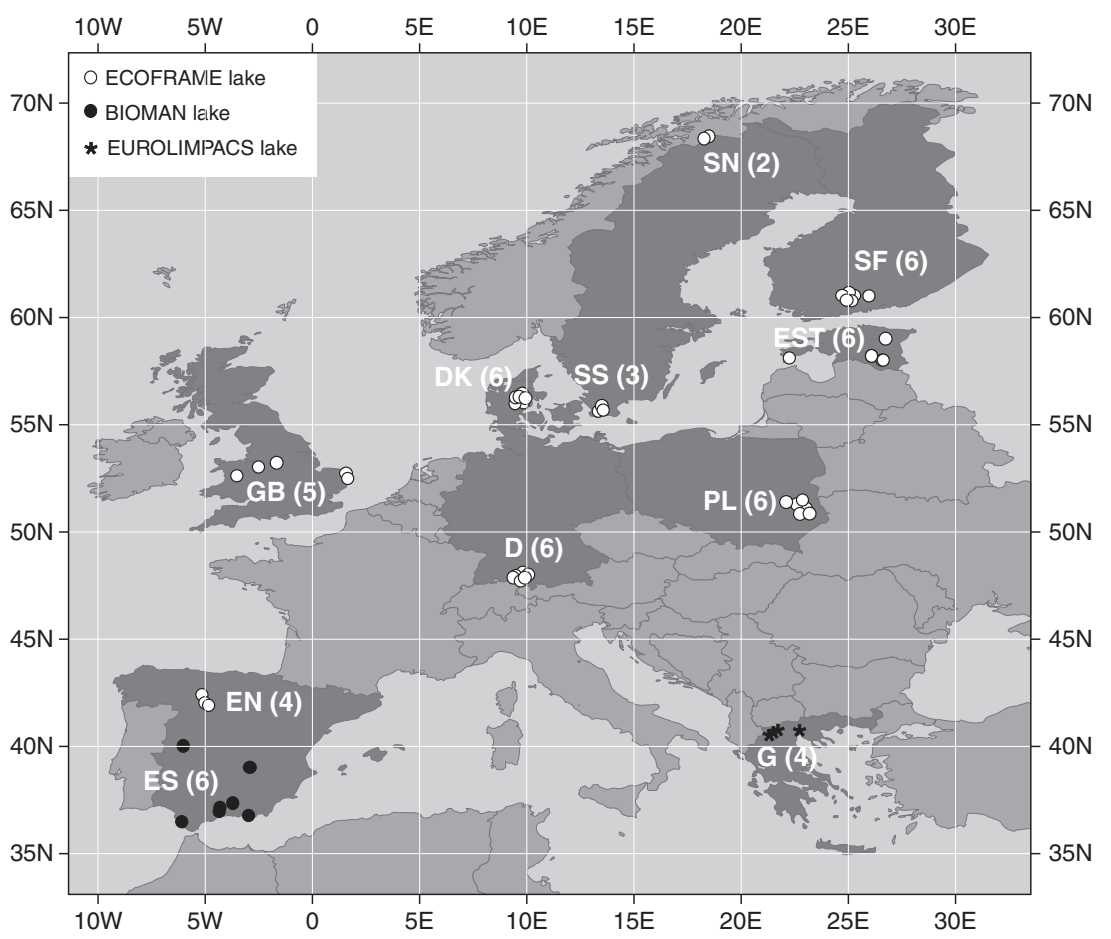


Table 1 Summary statistics of environmental variables from the 54 European study lakes

\begin{tabular}{|c|c|c|c|c|c|c|c|c|}
\hline Parameter & Mean & Median & $\begin{array}{l}25 \% \\
\text { percentile }\end{array}$ & $\begin{array}{l}75 \% \\
\text { percentile }\end{array}$ & Min & Max & $N$ & Transformation \\
\hline Latitude $\left({ }^{\circ} \mathrm{N}\right)$ & 51 & 53 & 42 & 58 & 36 & 68 & 54 & $\log _{10} x$ \\
\hline Longitude $\left({ }^{\circ} \mathrm{E}\right)$ & 13 & 12 & 4 & 23 & -6 & 27 & 54 & $\log _{10}(x+10)$ \\
\hline Area (ha) & 782 & 24 & 9 & 60 & 1 & 27000 & 54 & $\log _{10} x$ \\
\hline Mean depth (m) & 1.92 & 1.60 & 1.20 & 2.50 & 0.47 & 6.00 & 54 & $\log _{10} x$ \\
\hline Total phosphorous $\left(\mu \mathrm{g} \mathrm{L}^{-1}\right)$ & 107 & 71 & 32 & 141 & 6 & 470 & 54 & $\log _{10} x$ \\
\hline Total nitrogen $\left(\mu \mathrm{g} \mathrm{L}^{-1}\right)$ & 1936 & 1365 & 992 & 2690 & 239 & 7710 & 54 & $\log _{10} x$ \\
\hline Chl $a\left(\mu \mathrm{g} \mathrm{L}^{-1}\right)$ & 47 & 24 & 8 & 58 & 1 & 331 & 54 & $\log _{10} x$ \\
\hline Secchi depth (m) & 1.5 & 1.1 & 0.6 & 2.2 & 0.2 & 5.6 & 54 & $\log _{10} x$ \\
\hline Secchimean depth & 0.9 & 0.6 & 0.4 & 1.1 & 0.1 & 4.6 & 54 & $\log _{10} x$ \\
\hline Conductivity $\left(\mu \mathrm{S} \mathrm{cm}{ }^{-1}\right)$ & 775 & 313 & 141 & 585 & 9 & 7229 & 54 & $\log _{10} x$ \\
\hline $\mathrm{pH}$ & 8.0 & 8.1 & 7.7 & 8.4 & 5.1 & 9.5 & 54 & - \\
\hline PVI submerged plants (\%) & 15 & 5 & 1 & 14 & 0 & 87 & 44 & $\log _{10}(x+1)$ \\
\hline Piscivorous fish $\left(\mathrm{kg} \mathrm{net}^{-1}\right.$ night $^{-1}$ ) & 0.9 & 0.3 & 0 & 1.1 & 0 & 4.5 & 35 & $x^{0.5}$ \\
\hline $\begin{array}{l}\text { Plankti-benthivorous fish } \\
\left(\mathrm{kg} \mathrm{net}^{-1} \text { night }^{-1}\right)\end{array}$ & 2.3 & 0.9 & 0.1 & 3.9 & 0 & 11.1 & 35 & $x^{0.5}$ \\
\hline $\begin{array}{l}\text { Mean air temperature of the } \\
\text { warmest } \\
\text { month of the year }\left({ }^{\circ} \mathrm{C}\right)\end{array}$ & 18.8 & 17 & 16.5 & 21 & 12 & 26.4 & 54 & $x^{0.5}$ \\
\hline $\begin{array}{l}\text { Mean annual temperature } \\
(1961-90)\left({ }^{\circ} \mathrm{C}\right)\end{array}$ & 8 & 8 & 6 & 10 & -3 & 16 & 54 & $(x+10)^{0.5}$ \\
\hline
\end{tabular}

$\mathrm{KOH}$ for 20 min and kept cold $\left(4^{\circ} \mathrm{C}\right)$ for maximum two weeks until counting was performed. Identification of cladoceran subfossils was undertaken by two persons from the same lab (one trained by the other to ensure comparable results) following Frey (1959), Røen (1995), Flössner (2000) and Alonso (1996), using binocular (100x, Leica MZ12) and inverted light (320x, Leitz Labovert FS) microscopes. Subfossils retained on a $140 \mu \mathrm{m}$ mesh sieve were quantified for the entire subsample. Subfossils retained on an $80 \mu \mathrm{m}$ mesh sieve were suspended in $100 \mathrm{~mL}$ de-ionised water and subsampled, yielding a count percentage of $2.5-40 \%$, depending on subfossil density. Generally, the most characteristic abundant part (carapace, head shield, resting egg etc.) of each subfossil was counted and the most abundant body parts found across all 54 lakes were included in the analyses. Counts were adjusted to represent individuals (e.g. number of carapace halves 2 , number of headshields 1 ).

Sampling of environmental variables (three physical and five chemical variables + macrophyte abundance) followed a standardised protocol described in detail by Moss et al. (2003) (ECOFRAME and EUROLIMPACS lakes) and Declerck et al. (2005) (BIOMAN lakes). A further description of chlorophyll $a$ (chl $a$ ) and nutrient [total phosphorous (TP) and total nitrogen (TN)] analyses can be found in Nõges et al.
(2003). Water samples for chemical analyses were taken once (EUROLIMPACS, BIOMAN) or twice (ECOFRAME) from the centre of the lake during summer with a depth-integrating tube sampler. Water temperature and Secchi depth transparency (20 $\mathrm{cm}$ disc) were recorded, and conductivity and $\mathrm{pH}$ were measured on unfiltered water using electronic field probes. Plant volume inhabited (Canfield et al., 1984) by submerged macrophytes (PVIsub) was measured in late summer by estimating macrophyte coverage and height along transects from the lake shore to the lake centre. A water glass was used to estimate coverage. If visibility was low samples were taken randomly along transects with a rake. At least $10 \%$ of the lake area was scanned for macrophytes. Catch per unit effort (CPUE) of plankti-benthivorous fish was obtained from average of gill net (14 different mesh sizes, $6.25-75 \mathrm{~mm}$ ) catches overnight in the littoral and pelagic zone (Moss et al., 2003; Declerck et al., 2005). Data on annual mean air temperature $\left(T_{\text {ann.mean }}\right)$ were obtained directly from meteorological records (1961-90) (New, Humble \& Jones, 2000), while mean air temperature of the warmest month of the year $\left(T_{\text {summer }}\right)$ was calculated according to Moss et al. (2003) or obtained from the websites: http://www.inm.es and http://www. hnms.gr. 


\section{Pre-adjustment of data before analyses}

Prior to the statistical analyses environmental data were transformed (Table 1) to obtain the best approximation to a normal distribution. For the ECOFRAME data set, chemical variables consisted of the mean of two measurements taken in July-August 2000. A combined variable, SecDep, was created by dividing Secchi depth with mean depth and used as a surrogate for the light exposure to the sediment and thus benthic production and the potential importance of benthic cladocerans. Accordingly, mean depth and Secchi depth were excluded as environmental variables. In ordinations, input species data were logtransformed concentrations of subfossils (number of subfossilss $\mathrm{dw}$ sediment). Accumulation rates to adjust for site specific sediment accumulation were not available. Therefore, concentrations of subfossils were converted into relative percentage abundance and arcsin transformed to stabilise variance (Legendre \& Legendre, 1998) in multivariate regression tree analysis (MRT).

Rarefied taxon richness (Legendre \& Legendre, 1998) (hereafter referred to as standardised taxon richness, STR) and taxon diversity estimated by Hill's N2 (Hill, 1973) were related to climate surrogate variables, such as $T_{\text {summer }}$ and latitude. The proportion of sexual reproduction versus parthenogenetical reproduction was estimated for Bosmina and Chydoridae as $100 \%$ times the sum of ephippia divided by the sum of parthenogenetic carapaces plus ephippia according to Jeppesen et al. (2003). The ephippia percentages were $\log _{10}+1$ transformed, and linear regressions were performed with $T_{\text {ann.mean }}, T_{\text {summer }}$ and chl $a$, the latter used as a surrogate for lake productivity. Multiple regression including $T_{\text {ann.mean }}$ $T_{\text {summer, }}$ chl $a$, latitude, plankti-benthivorous and piscivorous fish biomass was performed to explore alternative explanatory variables on a subset of lakes with fish data available $(n=35)$. Significance level $(P<0.05)$ was adjusted by Bonferroni correction.

\section{Ordinations}

Redundancy (collinearity) among the environmental variables was explored by standardised principal components analysis (PCA) of the environmental variables shown in Table 1 (except for mean depth, Secchi depth, PVIsub and fish data) and by variance inflation factors (VIF) (ter Braak, 1995) for all lakes and for a subset of lakes with PVIsub data. Unimodal ordination was applied when the gradient length of axis 1 in detrended canonical correspondence analysis (DCCA, detrending by segments) exceeded 3.0 standard deviation (SD) units of turnover; otherwise, linear ordinations were applied (ter Braak, 1995). Pearson correlation between sample scores of correspondence analysis (CA) and canonical correspondence analysis (CCA) were used to indicate how well the environmental variables accounted for amonglake variation in cladoceran taxonomic composition (Lepš \& Šmilauer, 2003). CCA with forward selection and partial CCA (pCCA) were used to identify the most important environmental variables. Likewise, for a subset of lakes $(n=44)$, investigated for PVIsub, DCCA, redundancy analyses (RDA, standardised) and partial RDAs (pRDA) were performed. After excluding the most distinct groups of lakes as revealed by MRT analysis (see below), additional ordinations (DCCA, standardised RDA) were conducted for the remaining lakes. As rare species may have an unduly large influence in ordinations (ter Braak \& Šmilauer, 2002), ordinations were also performed on reduced data sets comprising taxa occurring in more than four lakes. These results are not presented as they did not deviate markedly from those of the total taxa community. Also ordination analyses performed on arcsine transformed percentage species input data, as used in the MRT analysis, showed similar results as for the log-transformed concentration data. $P$-values of Monte Carlo permutation tests, with 999 random permutations, were Bonferroni corrected (significance level: 5\%). All ordinations were performed in CANOCO version 4.5 (ter Braak \& Šmilauer, 2002).

\section{Multivariate regression trees}

Multivariate regression tree analysis (Déath, 2002) was performed using the environmental variables given in Table 1 (mean depth and Secchi depth were replaced by SecDep). MRT forms clusters of species and sites modelled from species and environmental relationships by repeated splitting of the data. Each split minimises the dissimilarity (sum of squared Euclidian distances, SSD) of the species and sites within clusters (Déath \& Fabricius, 2000). The overall fit of a tree is given by the relative error (RE: SSD in 
clusters divided by SSD in unsplit data), whereas the predictive accuracy is specified as cross validated relative error (CVRE) (Breiman et al., 1984; Déath, 2002). The model with the minimum cross-validated error (after 1000 cross validations) was selected as the final tree (Déath \& Fabricius, 2000). Species characteristics for a given cluster defined by the MRT analysis were identified using INDVAL (indicator species index) calculated as the product of the relative abundance and frequency of occurrence of each taxon within the cluster (Dufrene \& Legendre, 1997). An INDVAL value of 1 indicates that the species is only abundant in one particular cluster, whereas a value of zero indicates a wide distribution among clusters. Significance of taxa association to the cluster was tested by permutation with 500 random iterations. Taxa with an indicator value $>0.25$ and with $P<0.01$ were considered as indicator species according to Dufrene \& Legendre (1997). MRT was carried out in R (The R Foundation for Statistical Computing Version 2.2.0) using the mvpart package (Multivariate Partitioning) and INDVAL analyses were performed applying the labdsv package (Dynamic Synthetic Vegephenomenology).

\section{Comparisons between MRT clusters}

Differences between groups of lakes (separated by MRT analysis) were tested with ANOva $(P<0.05$, Tukey's test of multiple comparisons to separate groups, transformation according to Table 1) on variables identified by MRT and ordination as having a significant influence on the species distribution. In addition, ephippia abundance (log-transformed), taxon diversity (square-root transformed) and standardised taxon richness (STR) were analysed for between-MRT group differences by ANOVA. Additionally, cladocerans were divided into three major habitat groups (pelagic, macrophyte-associated and macrophyte/sediment-associated + sediment-associated taxa, for taxa association see Fig. 2) and three size classes: large $(\geq 1 \mathrm{~mm})$, medium (between $0.5-1 \mathrm{~mm}$ ) and small $(<0.5 \mathrm{~mm})$ according to Alonso (1996), Flössner (2000) and Røen (1995). The relative distribution of between-MRT groups was tested by ANOVA on arcsin-transformed percentage data for pelagic taxa and small and large-sized taxa. Welsch's ANOvA was used when Bartlett's test of equal variance indicated heterogeneity (Sokal \& Rohlf, 1981).

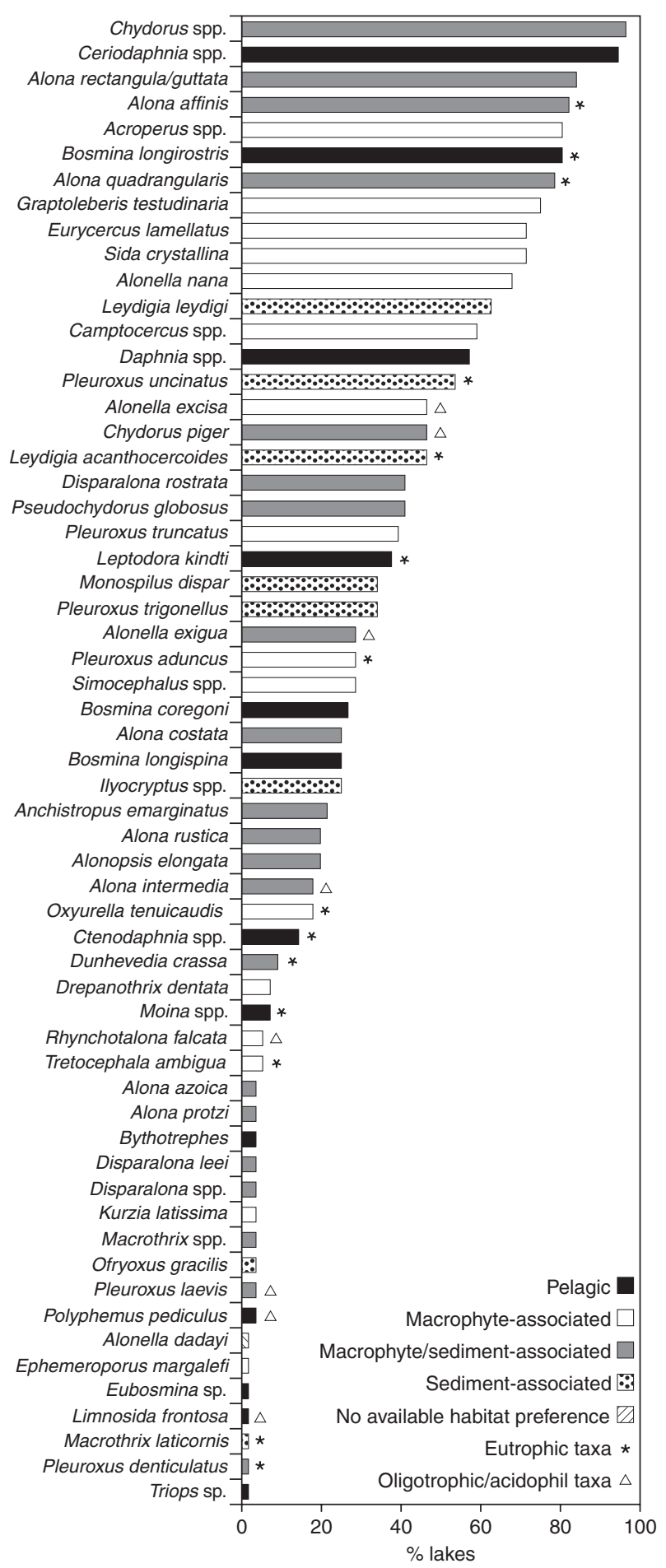

Fig. 2 Frequencies of taxa observations in the 54 European lakes. Taxa are divided into four different groups of preferred habitat according to Flössner (2000) and Alonso (1996). Taxa indicative of eutrophic waterbodies are marked with a star, taxa indicative of oligotrophic/acidic waterbodies with a triangle. 


\section{Results}

\section{Relations between environmental variables}

Several of the environmental variables were strongly correlated with the first PCA axis, indicating collinearity. The first PCA axis explained $89 \%$ of the variation in the environmental variables, compared to $7 \%$ by the second PCA axis. Only SecDep was correlated with the second PCA axis. On a subset of data allowing inclusion of abundance of submerged macrophytes, PVIsub ( $n=44$ lakes), a similar pattern was observed; the first and second PCA axes explained $88 \%$ and $7.1 \%$ respectively. Both PVIsub and SecDep were correlated with the second PCA axis 2 .

\section{Taxon richness and diversity}

A total of 59 cladoceran taxa were identified in the surface sediment of the 54 lakes. The most common taxa were Chydorus spp. and Ceriodaphnia spp., occurring in 54 and 53 lakes, respectively (Fig. 2). Bosmina longirostris had the highest concentration as well as the highest relative abundance, followed by Chydorus spp. being the second most abundant taxon. Twentyone taxa were considered as rare (found in less than five lakes) (Fig. 2), of which eight were found solely in the southern lakes (EN, ES, G). Median STR was 12, and a maximum STR of 19 taxa was observed in two Polish lakes (PL_1, PL_6) and one Estonian (EST_1) lake. The lowest STR (three taxa) occurred in two southern lakes (G_4, ES_11). STR and Hill's N2 taxon diversity increased significantly with latitude (Fig. 3) (square root-transformation of diversity measures: (Pearson $r_{\mathrm{STR}}=0.54, P<0.0001, n=54$ and Pearson $\left.r_{\text {diversity }}=0.45, P=0.0006, n=54\right)$ and decreased with $T_{\text {summer }}$ (Pearson $r_{\text {STR }}=-0.57, P=0.0001, n=54$ and Pearson $r_{\text {diversity }}=-0.56, P<0.0001, n=54$ respectively), but the relationships tended to be weaker at higher latitudes.

\section{Ordinations - all 54 lakes}

Correlation between sample scores of an unconstrained CA and constrained CCA showed that the 11 environmental variables explained most of the among-lake variation in cladoceran community composition (CACCA axis 1: Pearson correlation: site score $r=0.91$, species score $r=0.78$; CACCA axis 2: site score $r=0.78$, species score $r=0.71$, all $P^{\prime}$ s $<0.0001$ ). In total, $37 \%$ of the variance was explained, of which CCA axis 1 explained $12 \%$ and axis 2 another $8 \% \quad\left(\lambda_{1}=0.270, \lambda_{2}=0.163\right)$. Latitude was highly correlated with $T_{\text {summer }}(\mathrm{VIF}=30$ and 16 , for the others only 2-8) and was therefore excluded from further analysis. Axis 1 correlated positively with
Fig. 3 Taxon richness (standardised taxa per lake) and Hill's N2 diversity index in relation to latitude and mean air temperature of the warmest month of the year ( $\left.T_{\text {summer }}\right)$. Symbols represent the different lake groups of the MRT analysis shown in Fig. 5.
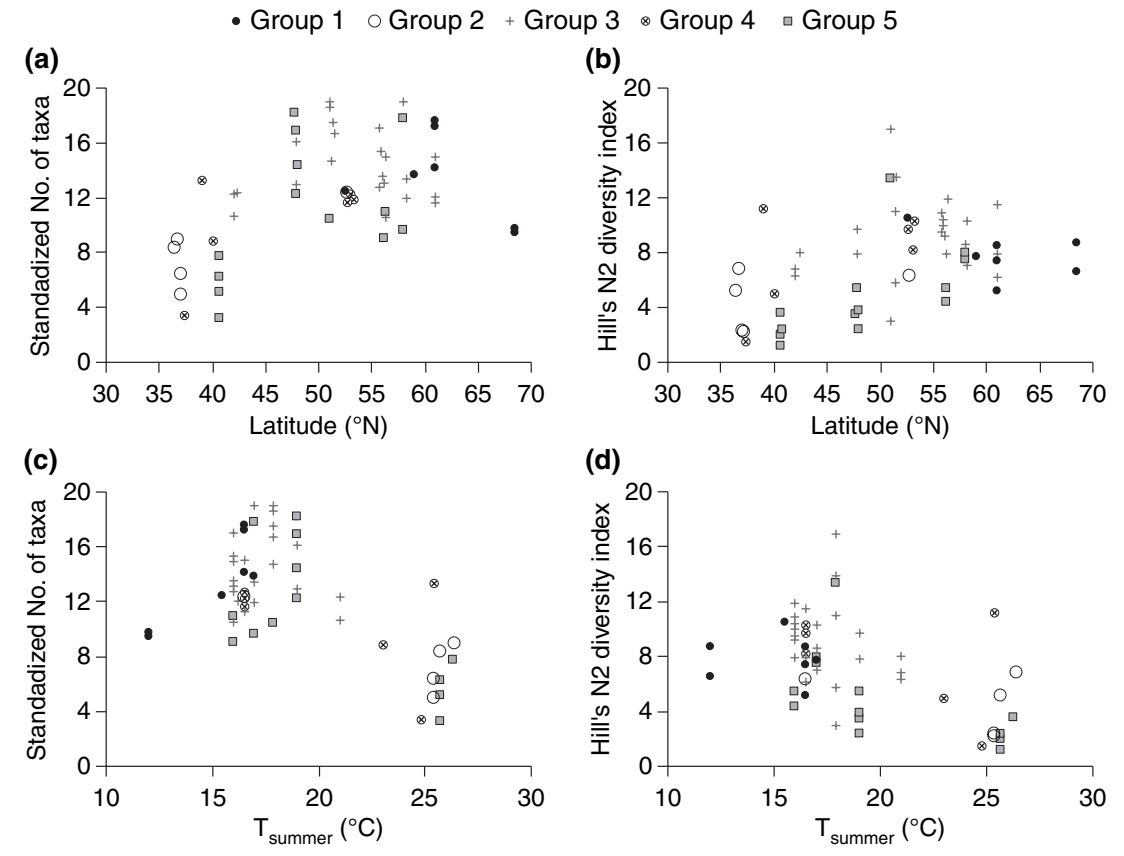

(d) 
conductivity, $T_{\text {summer }}$ and $T_{\text {ann.mean. Partial CCA }}$ showed that these two variables and longitude explained significant amounts of the variance (individually the three variables explained between $4 \%$ and $6 \%$, combined they explained $23 \%$ ). Total N, TP and $\mathrm{pH}$ correlated significantly with these variables (Fig. 4). The majority of the northern lakes grouped in the top-left quarter and the southern lakes in the topright quarter of the CCA ordination, indicating the importance of gradients in $T_{\text {summer }}$ and $T_{\text {ann.mean }}$ (Fig. 4).

\section{Ordinations - all 44 lakes with macrophyte data}

RDA $\left(\lambda_{1}=0.101, \lambda_{2}=0.075\right)$ conducted only on the subset of lakes for which PVIsub data were available (DCCA gradient length $2.4 \mathrm{SD}$ ) showed that conductivity, $T_{\text {summer }}$ and longitude contributed significantly and PVIsub marginally to the variation in cladoceran community composition (latitude was excluded due to high VIF), explaining in total $21 \%$ of the variation (conductivity $7 \%$, longitude $6 \%, T_{\text {summer }}$ and PVIsub each $4 \%$ ). PVIsub correlated positively with $T_{\text {summer }}$ and conductivity, but negatively with SecDep. All significant variables correlated with RDA axis 1, except longitude which correlated with RDA axis 2.

\section{MRT analyses - all 54 lakes}

MRT analyses including 10 environmental variables (latitude excluded) showed that a three-leaved tree had the highest accuracy (CVRE $=0.914)$ (Fig. 5a), explaining $67 \%$ of the variation in among-lake taxonomic composition. The first split separated seven lakes having low conductivity $\left(<46 \mu \mathrm{S} \mathrm{cm}^{-1}\right)$ (SN3, SN5, FIN1, FIN2, FIN3, EST4, UK5) (Fig. 5a). These lakes were also characterised by low $\mathrm{pH}(<7)$, low $T_{\text {ann.mean }}\left(<4.5^{\circ} \mathrm{C}\right)$ and relatively low nutrient level concentrations (median $\mathrm{TP}=11.4 \mu \mathrm{g} \mathrm{L}{ }^{-1}$, median $\mathrm{TN}=362 \mu \mathrm{g} \mathrm{L}^{-1}$, median Chl $\left.a=4.9 \mu \mathrm{g} \mathrm{L}^{-1}\right)$. Several taxa associated with oligotrophic and/or acidic water [e.g. Bosmina longispina (Leydig, 1860), Alonella excisa (Fischer, 1854), Alona rustica (Scott, 1895), Alona intermedia (Sars, 1862)] were among the indicator taxa for these lakes.

The second split was also defined by conductivity, separating five mainly warm water lakes with conductivity above $2210 \mu \mathrm{sm}^{-1}$ (ES7, ES9, ES10, ES12, UK3) (Fig. 5a). Three of these lakes were productive
(TP $>142 \mu \mathrm{g} \mathrm{L}^{-1}$, Chl $a>150 \mu \mathrm{g} \mathrm{L}^{-1}$ ), whereas two were less productive $\left(\mathrm{TP}<33 \mu \mathrm{g} \mathrm{L}^{-1}, \quad \mathrm{Chl}\right.$ $a<7 \mu \mathrm{g} \mathrm{L}^{-1}$ ). Macrophyte-associated taxa dominated this group, whereas indicators for the remaining 42 lakes consisted of pelagic or benthic species $[B$. longirostris (Müller, 1785), Leydigia leydigi (Schoedler, 1858) and Pleuroxus uncinatus (Baird, 1850)] (Fig. 5a).

\section{Ordination and MRT - high and low conductivity lakes excluded}

An additional ordination was conducted to investigate whether grouping occurred among the remaining 42 lakes with intermediate conductivity (REST). The environmental variables explained in total $39 \%$ of the taxa variation; $T_{\text {summer, }}$ longitude and $\mathrm{Chl} a$ contributed significantly, and explained in total $17 \%$ of the variation $(7 \%, 6 \%$ and $4 \%$ respectively).

The best predictive mode of MRT on cladoceran data from the 42 lakes did not reveal a split. In accordance with Breiman et al. (1984), the rule of selecting the most complex tree within 1 standard error of the best predictive tree was applied with the constraint that the smallest resulting group included more than three lakes. The resulting three-leaved MRT $(C V R E=1.04)($ Fig. $5 b)$ explained $69.4 \%$ of the community variance. The first split divided the lakes according to conductivity (threshold: $<344 \mu \mathrm{S} \mathrm{cm}^{-1}$ ). $T_{\text {ann.mean }}$ was less than $7.9^{\circ} \mathrm{C}$, except for three EN lakes. Alonella nana (Sars, 1862) was significantly associated with these 23 low-conductivity lakes (Fig. 5b).

The second split, attributed to longitude (Fig. 5b), separated six East European lakes with overall lower $\mathrm{Chl} a$, lower $\mathrm{pH}$ and higher SecDep from the remaining lakes. Indicator taxa for these lakes were mostly large-sized pelagic cladocerans, whereas the smaller pelagic species $B$. longirostris was significantly associated with the remaining group of lakes. These lakes were characterised by relatively high Chl $a$ and low SecDep. Similar results were revealed when excluding taxa occurring in less than three lakes.

\section{Ephippia to carapace ratios}

Bosmina were the most abundant ephippia, occurring in 46 of the 49 lakes inhabited by this taxon, and Chydoridae ephippia were found in 50 out of the 54 lakes. The proportion of ephippia compared to body 
(a)

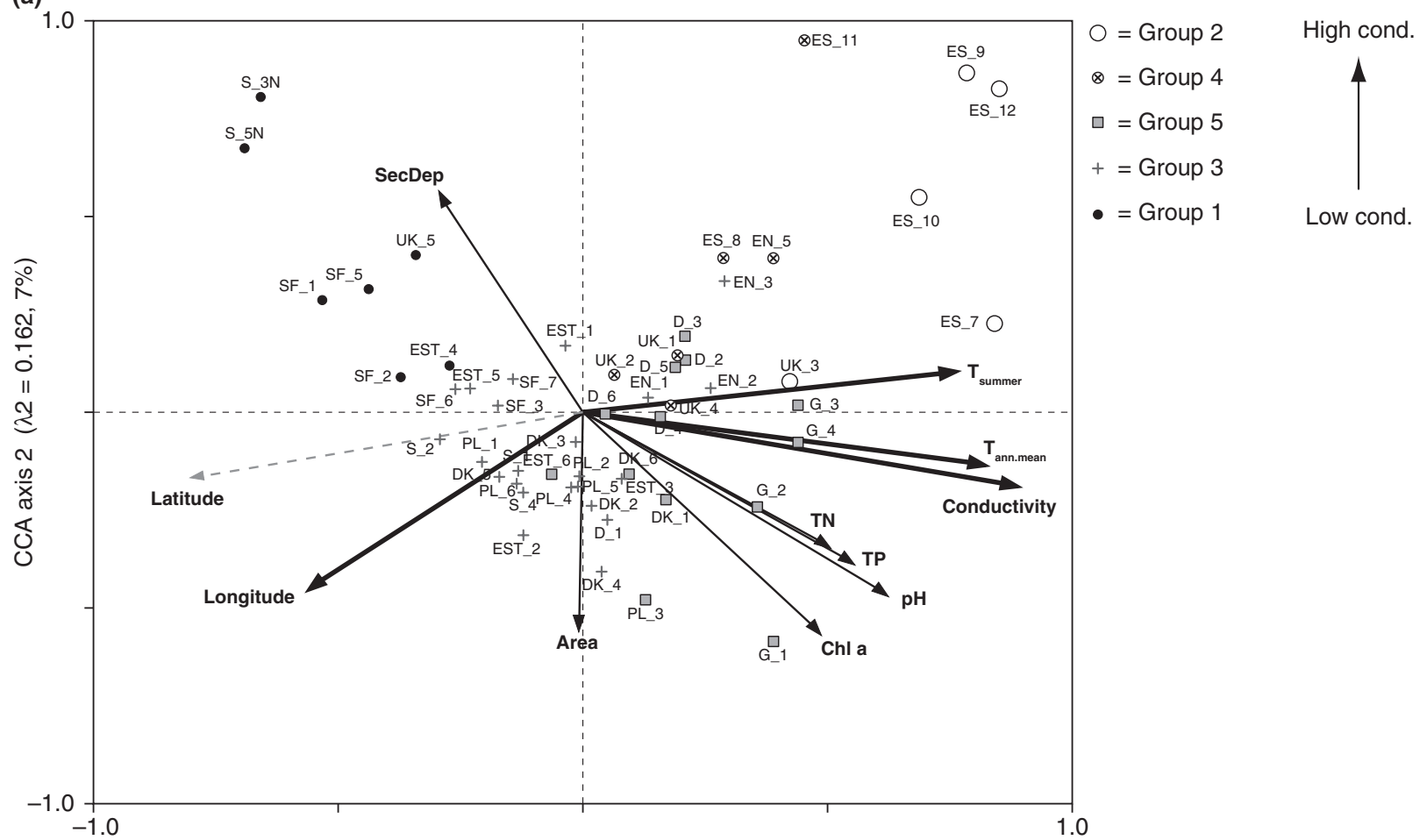

(b)

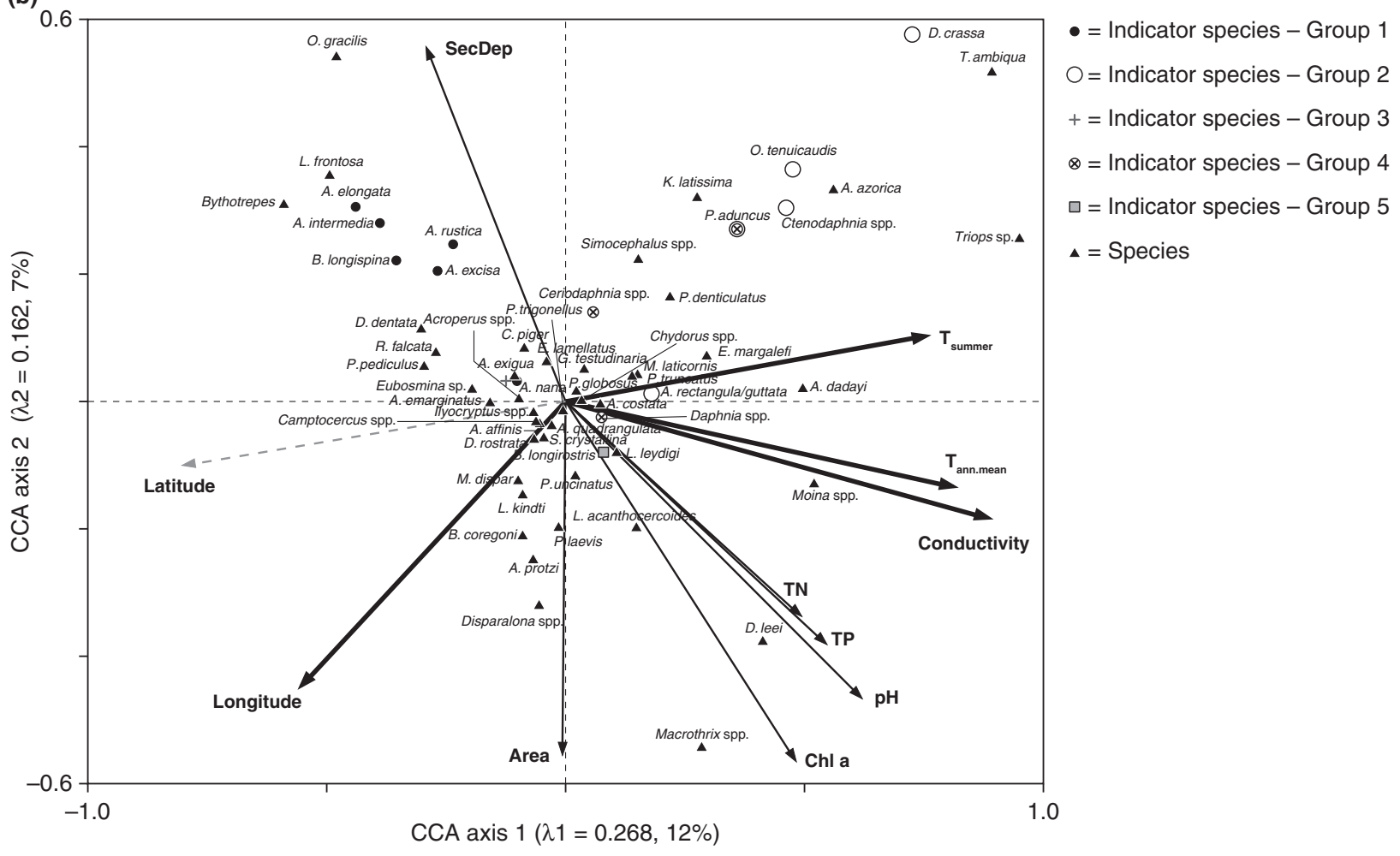

Fig. 4 CCA ordination plot of the 54 European lakes, including 10 environmental variables explaining in total 35\% of the among-lake variation in taxonomic composition (latitude plotted as passive variable). Sites (a) and 59 cladoceran taxa (b). Solid arrows indicate significant variables determined by forward selection and Bonferroni-adjusted $P$-values. Site symbols and species symbols refer to the MRT division in groups and identified indicator species (Fig. 5). Country abbreviations identical with Fig. 1. 
(a1)

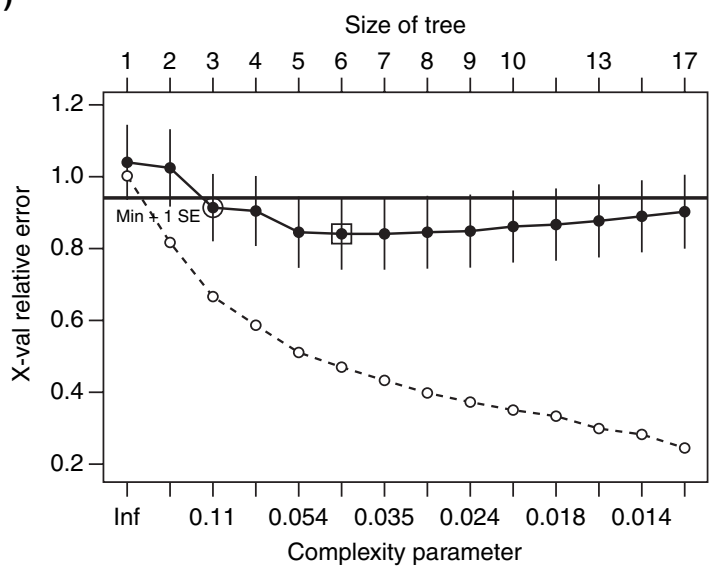

(a2)

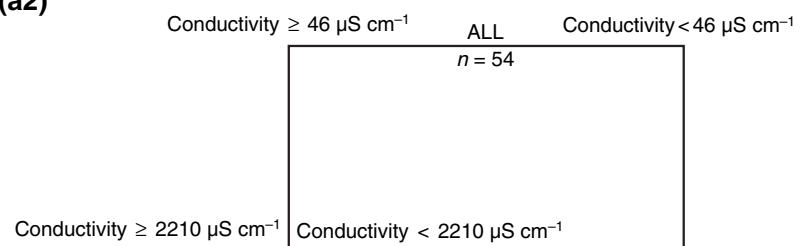

(b1)

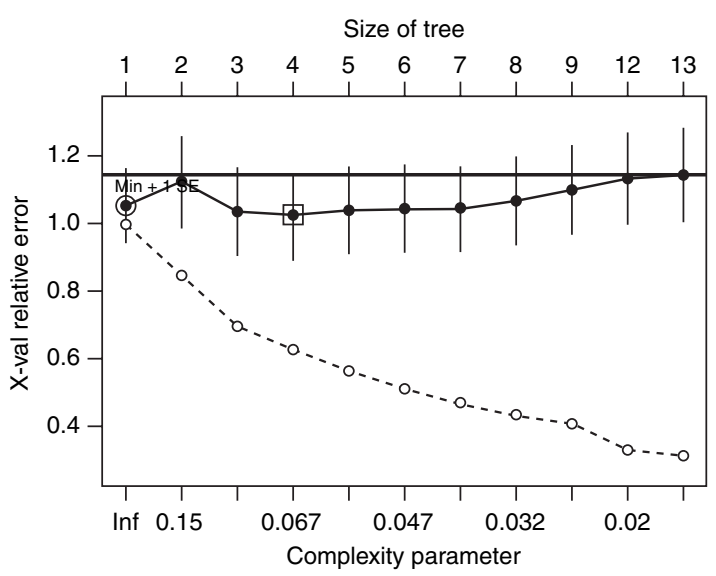

(b2)
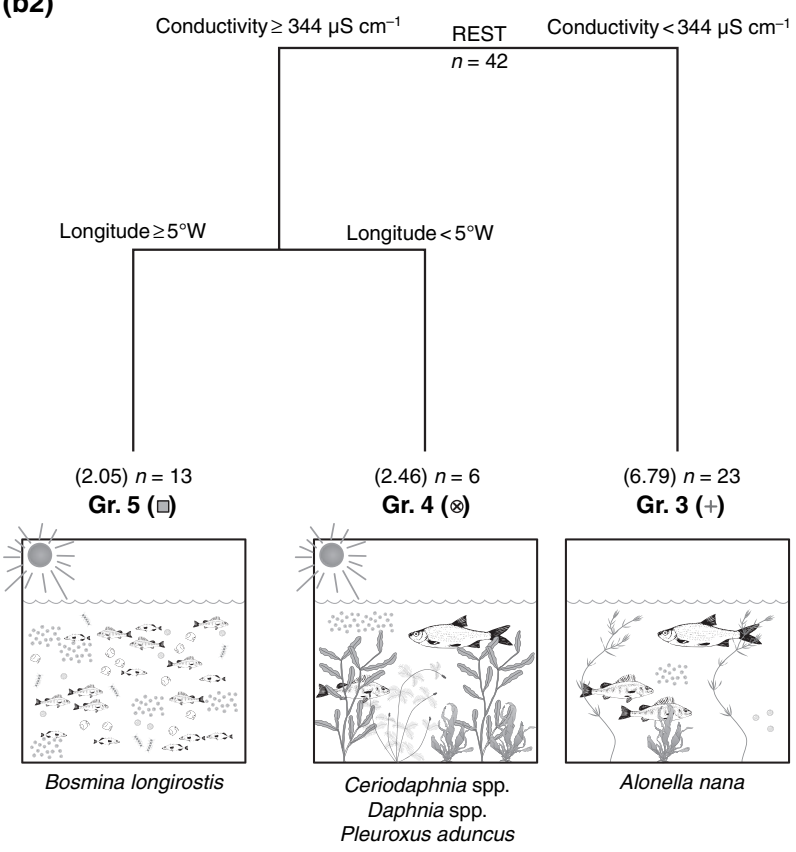

Fig. 5 Multivariate regression tree based on cladoceran remains from 54 European lakes (a) and with the exclusion of low- and high-conductivity lakes (groups 1 and 2) (b). Showing the tree with greatest cross validated accuracy (a) and the three-leaved tree within 1 standard error (b). Number of lakes per group $(n)$ and indicator taxa are given for each group and deviance (SSD) is given in brackets. Illustrative figures of the 'typical' lake, based on present data and knowledge about ecosystem structure (Declerck et al., 2005; Moss et al., 2003; authors' unpubl. data), are shown beneath each group.

shields was highest in the two northern-most lakes (33\% and $40 \%$ for Bosmina and $10 \%$ and $15 \%$ for chydorids), and generally low in the more southern lakes $(<1 \%$ for Bosmina primarily in G, PL, D, and UK lakes and $<0.5 \%$ for Chydoridae primarily in ES, G and UK lakes). Intermediate to high ephippia ratios for chydorids $(>1 \%)$ were found primarily in $\mathrm{SN}, \mathrm{SF}$ and DK lakes and for Bosmina (>2\%) in SN, SF, EST and UK lakes as well as in three EN lakes. Ephippia percentages of both Bosmina and chydorids showed a weak but significant negative relation to climate variables: $T_{\text {summer }}\left(F=15.14, r^{2}=0.24, P=0.0003\right.$; $F=24.13, \quad r^{2}=0.32, \quad P<0.0001$ respectively) and $T_{\text {ann.mean }}\left(F=20.82, r^{2}=0.31, P<0.0001 ; F=32.51\right.$, $r^{2}=0.38, P<0.0001$ respectively) as well as to Chl $a$ $\left(F=22.67, r^{2}=0.33, P<0.0001 ; F=11.59, r^{2}=0.18\right.$, 
$P=0.0013$ respectively). Multiple linear regression, including several potential variables controlling ephippia production: $\mathrm{Chl} a$ (food source), $T_{\text {ann.mean }}$ $T_{\text {summer }}$ (climate) and plankti-benthivorous and piscivorous fish biomass (predation) identified $T_{\text {ann.mean }}$ as a significant variable for both Bosmina and chydorids $(t$-value $=-3.65, P=0.0011 ; t$-value $=-4.87, \quad P<0.0001$ respectively), while $\mathrm{Chl} a$ was only marginally significant $(t$-value $=-2.43$, $P=0.0221 ; t$-value $=-2.16, P=0.0393$ respectively).

\section{Characteristics of the different MRT groups of lakes}

Lake groups identified by MRT differed most notably in conductivity (Fig. 6). Low conductivity lakes were characterised by cold climate, low nutrient and $\mathrm{Chl} a$ conditions, as well as by low PVIsub. Fish biomass was low and piscivorous species prevailed. Correspondingly, the cladoceran community was dominated by large-sized pelagic taxa and ephippial production was high. In contrast, high conductivity lakes were characterised as warm-water lakes (except for UK-3), generally with high submerged macrophyte coverage ranging from $34 \%$ to $100 \%$ (mean $72 \%, n=3$ ES lakes), one being hypertrophic (TP $\left.=462 \mu \mathrm{g} \mathrm{L}^{-1}\right)$ with no fish and two being meso-

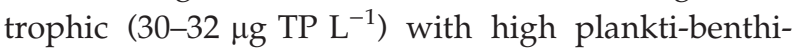
vorous CPUE (>4610 kg net ${ }^{-1}$ night $^{-1}$ ) (Fig. 6a-h). Unfortunately, PVIsub was only measured for one of these lakes (6\% in UK-3), making tests including PVIsub impossible. Within this group the cladoceran community was dominated by small and mediumsized macrophyte-associated and macrophyte/sediment-associated taxa (Fig. 6m-o). The three remaining groups (REST) differed significantly in conductivity (Fig. 6a), but not in temperature $\left(T_{\text {ann.mean }}\right)$ and TP (Fig. 6b-d). However, group 5 (including D, PL, EST, DK and all G lakes) tended to have high Chl $a$ and low Secchi depth as well as low PVIsub, and this group deviated clearly from group 3 and 4 by having low taxon diversity and a predominance of pelagic taxa (Fig. 6e-g,j,p). Also, the proportion of Bosmina ephippia was generally low (Fig. 6k). The cladoceran community of group 3 and 4 resembled each other with respect to preferred habitats of the cladocerans. Indeed, the only significant variable separating these groups was conductivity, although tendencies to lower Chl $a$ and higher SecDep and PVIsub were observed in group 4 (Fig. 6a-f).

\section{Discussion}

We found clear differences in cladoceran community structure, taxon richness and ephippia to body shield percentage along the European latitude gradient studied here. However, latitude, and therefore also temperature, correlated with lake conductivity and nutrient concentrations, precluding a clear extraction of a direct climate signal. For example, ordination showed that temperature and conductivity explained almost equal amounts of variation in the entire cladoceran species data set. Similarly, MRT indicated correlation between conductivity, $\mathrm{pH}$, temperature and nutrients.

The MRT analysis divided the 54 European lakes into three major groups. The first group, consisting of seven mainly northern low-conductivity lakes, was characterised by acid-tolerant species (Røen, 1995; Flössner, 2000) (Fig. 5). Similarly, de Eyto et al. (2003) found $\mathrm{pH}$ and latitude to be the most important variables determining contemporary littoral chydorid communities in a study of 59 European lakes, of which 44 are included in the present study. Moreover, these authors found a significantly negative correlation between $\mathrm{pH}$ and the abundance of five species, three of which (Alonopsis elongata, A. excisa and Alona rustica) were indicator species of the acidic, low conductivity lakes in our study. Low conductivity lakes were also nutrient poor, with high light penetration (high SecDep) but low macrophyte abundance (PVIsub). High transparency likely results in high benthic production of algae and mosses (Liboriussen \& Jeppesen, 2003; Vadeboncoeur et al., 2003), which may explain the relatively large abundance of macrophyte- and sediment-associated taxa despite the low PVIsub. Moreover, the lakes had a low abundance of planktivorous fish, explaining the proportionally high abundance of large-sized species, as has been noted from other studies of contemporary data and cladoceran subfossils in Faroese lakes (Amsinck et al., 2005).

The second group, consisting of five lakes with high conductivity located mainly in southern-most Spain, was characterised by the absence of Bosmina and the presence of small eutrophic and macrophyte-/sediment-associated taxa such as Dunhevedia crassa (King, 1853), Oxyrella tenuicaudis (Sars, 1862) and Pleuroxus aduncus (Jurine, 1820) (Fig. 4a,b). The lakes were meso- to hypertrophic, had an overall high percentage of macrophyte cover and were dominated by small 
R. Bjerring et al.

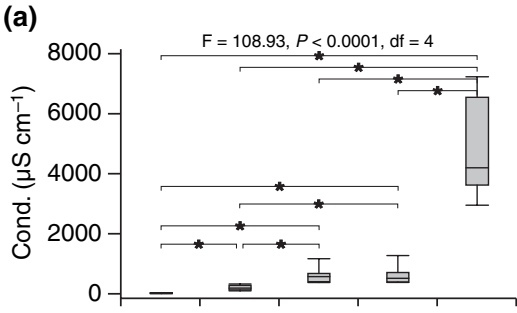

(b)

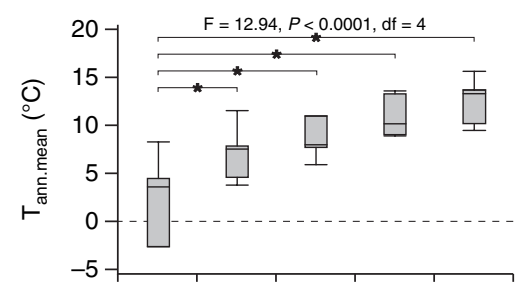

(c)

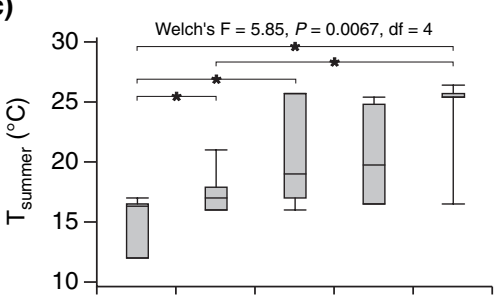

(d)

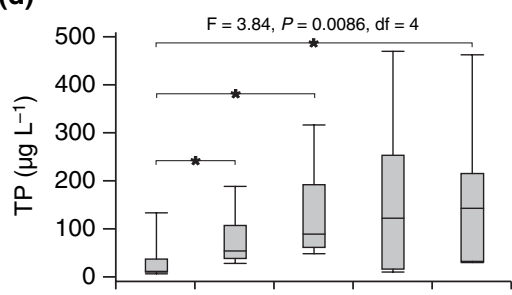

(e)

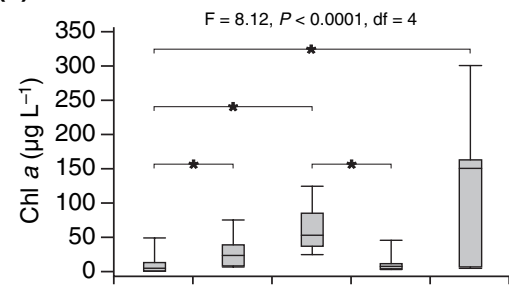

(f)

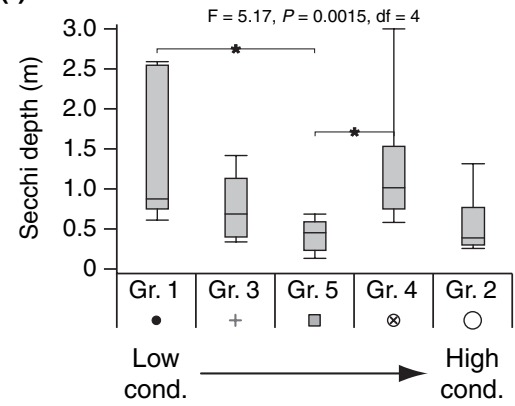

(g)

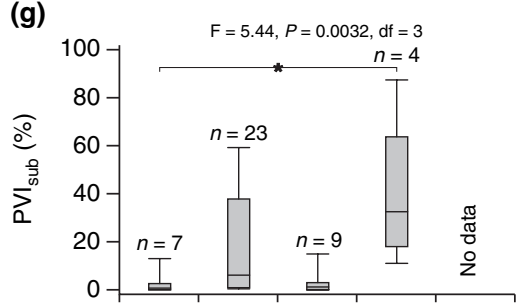

(h)

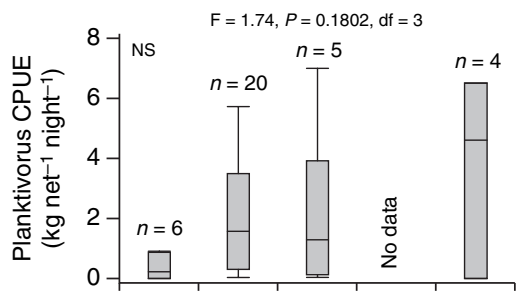

(i)

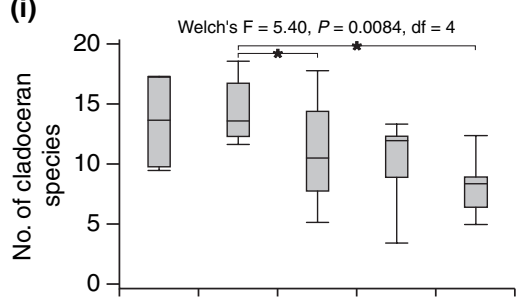

(j)

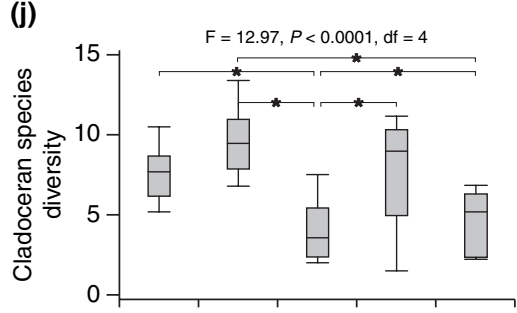

(k)

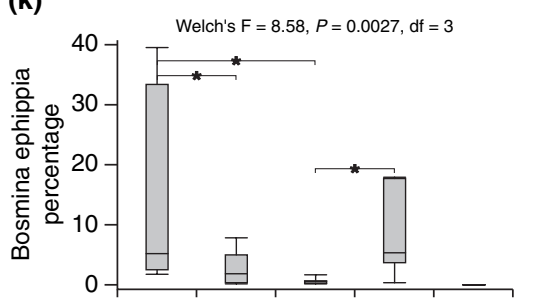

(I)

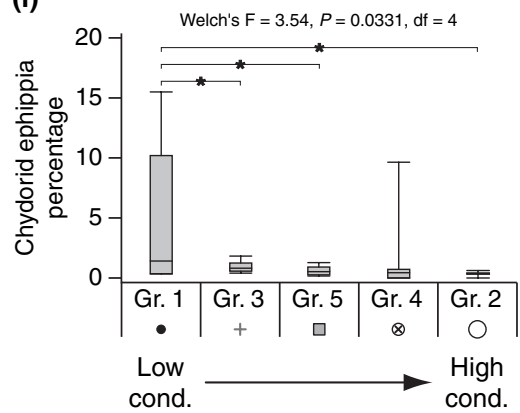

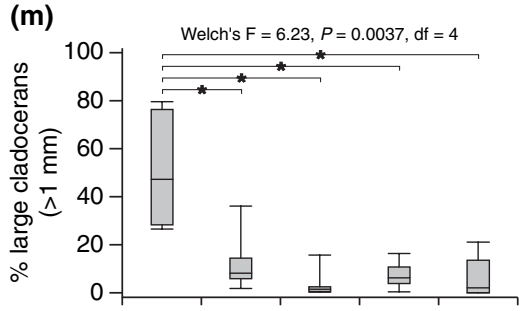

(n)

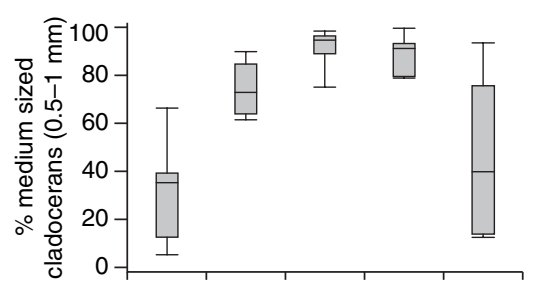

(o)

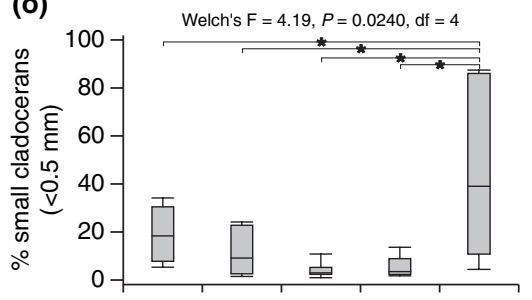

(p)

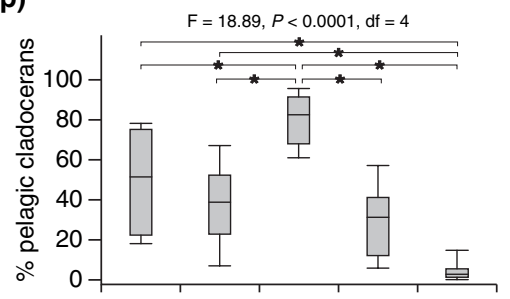

(q)

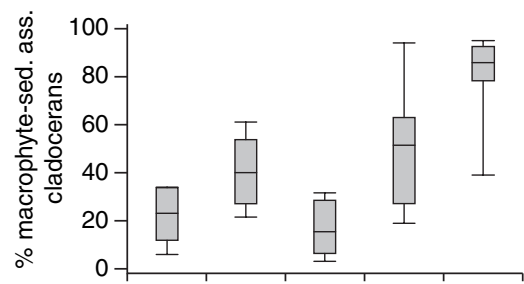

(r)

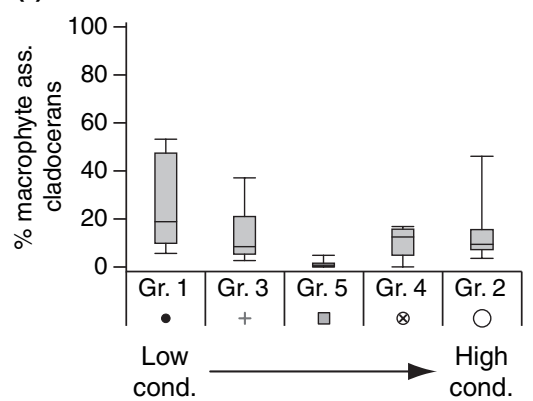


Fig. 6 The distribution (median, 25 and 75 percentiles [boxes] 10 and 90 percentiles [whiskers]) of selected variables divided into lake groups defined by MRT, group numbers and symbols refer to those in Fig. 5. (a) conductivity, (b,c) mean annual (1961-90) and monthly air temperature of the warmest month $\left({ }^{\circ} \mathrm{C}\right)$, (d) total phosphorus (TP), (e) chlorophyll $a$, (f) Secchi depth, (g) volume of submerged macrophytes (PVIsub), (h) CPUE of plankti-benthivorous fish (kg net ${ }^{-1}$ night $^{-1}$ ), (i) standardised taxon richness, (j) Hill's N2 taxon diversity, (k) the percentage of Bosmina ephippia relative to Bosmina ephippia + body shields, (l) the percentage of chydorid ephippia relative to chydorid ephippia + body shields, the relative contribution of (m) large-sized cladocerans ( $>1 \mathrm{~mm})$, (n) mediumsized cladocerans $(0.5-1 \mathrm{~mm})$ and $(\mathrm{o})$ small cladocerans $(<0.5 \mathrm{~mm})$, the relative contribution of (p) pelagic cladocerans, (q) macrophyte/sediment-associated + sediment-associated cladocerans, and (r) macrophyte-associated cladocerans. F denotes ANOvA test where variance heterogeneity occurred, Welch's F-test was applied. *Significant difference $(\alpha=0.05)$ between groups (Tukey's multiple comparisons). NS = no significant differences between groups. Arcsin-transformation was applied to percentage data before statistical tests. Where observation numbers deviate from those given in Fig. 5, numbers $(n)$ are given above the box.

cladoceran taxa. Dominance of small forms despite high macrophyte abundance agrees with the recent findings that aquatic macrophytes do not provide adequate refuge to zooplankton in Mediterranean (Castro, Marques \& Goncalves, 2007) or subtropic shallow (Meerhoff et al., 2007a) lakes because of high fish density (Gyllström et al., 2005) even within macrophyte beds (Castro et al., 2007; Ortega-Mayagoitia, Armengol \& Rojo, 2000; Blanco et al., 2003; Romo et al., 2004; Meerhoff et al., 2007b). That fish are strong predators in these lakes is supported by data from two fishless, hypertrophic lakes in southern Spain (ES); these two lakes had the highest observed relative abundance of large-sized Ctenodaphnia (2\% and 10\%). Species belonging to the Ctenodaphnia group (D. magna, D. mediterranea) are recognised as being tolerant of high salinity and nutrient concentrations (Boronat, Miracle \& Armengol, 2001; Goncalves et al., 2007) but disappear in lakes where fish are abundant (Jakobsen et al., 2003).

Conductivity was an important predictor of zooplankton community composition even when low and high conductivity lakes were excluded (MRT group 1 and 2) (Fig. 5b). Our findings support those of Hobæk, Manca \& Andersen (2002), who showed conductivity to be a key predictor of both zooplankton species composition and richness in a Norwegian regional lake study as well as in a study of 123 lakes covering a European gradient from Norway to Spain. We found three groups in this mid conductivity dataset. An indicator species of group 3 (Fig. 5b), characterised by relatively low conductivity, temperature and $\mathrm{TP}$, was the small sized A. nana. According to Flössner (2000) and Brodersen, Whiteside \& Lindegaard (1998) this species is associated with medium TP levels (25$40 \mu \mathrm{g} \mathrm{L}^{-1}$ ) and often with high PVI. The remaining 19 high-conductivity lakes (MRT group 4 and 5) (Fig. 5b), separated by longitude, differed with re- spect to $\mathrm{Chl} a$ and turbidity. The lakes with low $\mathrm{Chl} a$ (group 4) were characterised by planktonic as well as macrophyte-sediment-associated taxa and tended to have a slightly higher percentage of large-sized taxa than group 5 (Fig. 6). The more nutrient rich and turbid group 5 lakes were dominated by small pelagic B. longirostris (Fig. 5b), known to be abundant in nutrient rich temperate lakes with high planktibenthivorous fish predation pressure (Dahl-Hansen, 1995; Jeppesen et al., 1996).

PVIsub was positively correlated with $T_{\text {summer }}$ and $T_{\text {ann.mean, }}$ thus providing increased habitat availability, in particular for substratum-dwelling cladocerans, and increased species richness (Declerck et al., 2007) in warmer lakes. A positive relationship between PVIsub and temperature was also obtained in the constrained ordination based on the subset of 44 of the study lakes, and supports findings from other studies (Durate \& Kalff, 1987; Rooney \& Kalff, 2000). Low water depth (Beklioglu, Altinayar \& Tan, 2006) and high fish grazing on periphyton (Meerhoff et al., 2007b; Teixeira-de Mello et al., 2009) and high temperature may favour macrophyte growth in the southern-most lakes and potentially result in increased taxon richness of cladocerans as an indirect climate response through increased macrophyte cover and water filled volume. However, the lowest STR occurred in the southern-most and warmest lakes (G, EN or ES lakes) despite high macrophyte coverage or PVIsub in these lakes. This finding agrees with a comparative study of the biodiversity in Danish, BelgianDutch and Spanish lakes (Declerck et al., 2005). These authors found a positive relationship between taxon richness of cladocerans and submerged macrophyte percentage coverage in Danish and BelgianDutch lakes, whilst low taxon richness and no correlation to macrophyte coverage were found for Spanish lakes. High conductivity and high 
fish predation are likely the reasons for low taxon richness in arid areas, indicating that taxon richness in European lowland lakes peaks at intermediate latitudes. However, low diversity can result from low evenness in the population. A comparison between sites based on taxon richness in samples may, therefore, be biased by variance in evenness. Overall, strong evidence of a latitudinal gradient exists, showing increasing species richness in freshwater systems towards the equator (Mittelbach et al., 2007). This was also the general finding of a meta-analysis of species richness and latitudinal gradients including almost 600 studies, although the gradients were weaker for freshwater than for marine and terrestrial studies (Hillebrand, 2004), perhaps because the species richness of lakes is modulated by conductivity and fish predation as well as by landscape barriers and possibly greater heterogeneity among limnic compared to marine waters.

We found the proportion of Bosmina ephippia to body shields in the two northern-most sub-arctic lakes to be high $(33 \%$ and $40 \%)$ but similar to the mean percentage (34\%) of arctic and sub-arctic lakes from Greenland (Jeppesen et al., 2003). The southernmost lakes generally had a low ratio, in particular for Bosmina. Multivariate regressions revealed that $T_{\text {summer }}$ was the most important variable determining variations in the ephippia:body shield ratio. For Bosmina, however, Chl $a$ also seemed important. The northern-most lakes (S_N, SF, EST) generally had both the lowest $\mathrm{Chl} a$ and the lowest mean $T_{\text {summer }}$ and $T_{\text {ann.mean. }}$. Therefore, climate (length of growing season) and low food availability could both induce the high proportion of resting ephippia. Analysing data from Greenland to Spain, Jeppesen et al. (2003) found summer air temperature to explain a large proportion of variation in the ratio for Bosmina.

In summary, the species composition of cladoceran subfossils in the surface sediments of 54 shallow lakes and environmental characteristics changed significantly with latitude. In the northern lakes, large-sized pelagic cladoceran taxa dominated (occasionally supplemented with acid tolerant species), whereas small and benthic-associated taxa prevailed in the southern lakes. Conductivity was an important predictor of differences in community composition, but nutrient state (and predation) and, indirectly, habitat availability were also important. In addition, a clear relationship between taxon richness and latitude was revealed, being low in the two northern-most lakes as well as in the southern-most productive and vegetation-rich lakes. Moreover, the proportion of ephippia was higher in northern lakes, where the season is shorter, and also related to the nutrient state. However, the correlative nature of the variables highlighted the difficulties of disentangling a strict climate signal from the indirect effects of climate and human-related impacts (such as nutrient enrichment and salinisation through cultivation) when the European latitude gradient is used as a climate proxy. Therefore, future studies using a similar approach should aim to include more study sites along a latitudinal gradient, but with nutrient concentration and conductivity gradients nested within ecoregions.

\section{Acknowledgments}

We are grateful to G. Velle, R.K. Johnson and an anonymous reviewer for their valuable comments improving earlier versions of the manuscript. We thank Karina Jensen for her contribution to the identification of sedimentary cladoceran remains as well as Søren Erik Larsen for performing the rarefraction analysis and statistical guidance. Also thanks to Anne Mette Poulsen for manuscript editing, Ane Kjeldgaard for producing the geographical map and Tinna Christensen for figure layout. The project was supported by the EU-funded projects ECOFRAME (EVK1-CT199900039), BIOMAN (EVK2-CT-1999-00046) and EUROLIMPACS (GOCE-CT-2003-505540) as well as the DK-funded CLEAR project (a Villum Kann Rasmussen Centre of Excellence project), The Research Council for Nature and Universe (272-08-0406) and SOAS (International School of Aquatic Science, University of Aarhus, Denmark). This paper is also a result of the Danish Galathea 3 expedition funded by The Danish Agency for Science, Technology and Innovation and represents Galathea publication No. P30.

\section{References}

Alonso M. (1996) Fauna Ibérica, Crustacea, Branchiopoda. In: Museo National de Ciencias Naturales (Eds M.A. Ramos, J.A. Terceder, X.B. Ros, J.G. Noguera, A.G. Sierra, E.M. Mayol, F.M. Piera, J.S. Marino \& J.T. González), pp. 486. Vol. 7. CSIC, Madrid.

Amsinck S.L., Jeppesen E. \& Ryves D. (2003) Cladoceran stratigraphy in two shallow brackish lakes with special 
reference to changes in salinity, macrophyte abundance and fish predation. Journal of Paleolimnology, 29, 495-507.

Amsinck S.L., Jeppesen E. \& Landkildehus F. (2005) Relationships between environmental variables and zooplankton subfossils in the surface sediments of 36 shallow coastal brackish lakes with special emphasis on the role of fish. Journal of Paleolimnology, 33, 39-51.

Amsinck S.L., Jeppesen E. \& Verschuren D. (2007) Cladoceran resting eggs and anthropogenic changes. In: Diapause in Aquatic Invertebrates: Role for Ecology, Physiology and Human Uses (Eds V. Alekseev \& B. De Stasio), pp. 135-157. Springer, Dordrecht, the Netherlands.

Battarbee R.W. (2000) Paleolimnological approaches to climate change, with special regard to the biological record. Quarternary Science Reviews, 19, 107-124.

Beklioglu M., Altinayar G. \& Tan C.O. (2006) Water level control over submerged macrophyte development in five shallow lakes of Mediterranean Turkey. Archiv für Hydrobiologie, 166, 535-556.

Beklioglu M., Romo S., Kagalou I., Quintana X. \& Becares E. (2007) State of the art in the functioning of shallow Mediterranean lakes: workshop conclusions. Hydrobiologia, 584, 317-326.

Blanco S., Romo S., Villena M. \& Martínez S. (2003) Fish communities and food web interactions in some Mediterranean lakes. Hydrobiologia, 506509, 473-480.

Boronat L., Miracle M.R. \& Armengol X. (2001) Cladoceran assemblages in a mineralization gradient. Hydrobiologia, 442, 75-88.

Bos D.G., Cumming B.F. \& Smol J.P. (1999) Cladoceran and Anostraca from the Interior Plateau of British Columbia, Canada, as paleolimnological indicators of salinity and lake level. Hydrobiologia, 392, 129-141.

ter Braak C.J.F. (1995) Ordination. In: Data Analysis in Community and Landscape Ecology (Eds R.H.G. Jongman, C.J.F. ter Braak \& O.F.R. van Tongeren), pp. 91-173. Cambridge University Press, Cambridge.

ter Braak C.J.F. \& Šmilauer P. (2002) CANOCO Reference Manual and CanoDraw for Windows. User's Guide. Software for Canonical Community Ordination (version 4.5). Microcomputer Power, Ithaca, New York.

Breiman L., Friedman J.H., Olshen R.A. \& Stone C.G. (1984) Classification and Regression Trees. Wadsworth International Group, Belmont, CA.

Brendonck L. \& De Meester L. (2003) Egg banks in freshwater zooplankton: evolutionary and ecological archives in the sediment. Hydrobiologia, 491, 65-84.

Brodersen K.P., Whiteside M.C. \& Lindegaard C. (1998) Reconstruction of trophic state in Danish lakes using subfossil chydorid (Cladocera) assemblages. Canadian Journal of Fisheries and Aquatic Sciences, 55, 1093-1103.
Canfield D.E., Shireman J.V., Colle D.E., Haller W.T., Watkins C.E. \& Maceina M.J. (1984) Prediction of chlorophyll a concentrations in Florida Lakes Importance of aquatic macrophytes. Canadian Journal of Fisheries and Aquatic Sciences, 41, 497-501.

Castro B.B., Marques S.M. \& Goncalves F. (2007) Habitat selection and diel distribution of the crustacean zooplankton from a shallow Mediterranean lake during the turbid and clear water phases. Freshwater Biology, 52, 421-433.

Dahl-Hansen G.A.P. (1995) Long-term changes in crustacean zooplankton - effects of a mass removal of Arctic charr, Solvalinus alpinus (L.), from an oligotrophic lake. Journal of Plankton Research, 17, 1819-1933.

Déath G. (2002) Multivariate regression trees: a new technique for modeling species-environment relationships. Ecology, 83, 1105-1117.

Déath G. \& Fabricius K.E. (2000) Classification and regression trees: a powerful yet simple technique for ecological data analysis. Ecology, 81, 31783192.

Declerck S., Vandekerkhove J., Johansson L. et al. (2005) Multi-group biodiversity in shallow lakes along gradients of phosphorus and water plant cover. Ecology, 86, 1905-1915.

Declerck S., Vanderstukken M., Pals A., Muylaert K. \& De Meester L. (2007) Plankton biodiversity along a gradient of productivity and its mediation by macrophytes. Ecology, 88, 2199-2210.

Dufrene M. \& Legendre P. (1997) Species assemblages and indicator species: the need for a flexible asymmetrical approach. Ecological Monographs, 67, 345-366.

Duigan C.A. \& Birks H.H. (2000) The late-glacial and early-Holocene palaeoecology of cladoceran microfossil assemblage at Kråkenes, western Norway, with a quantitative reconstruction of temperature changes. Journal of Paleolimnology, 23, 67-76.

Dumont H.J. (1994) On the diversity of the Cladocera in the Tropics. Hydrobiologia, 272, 27-38.

Durate C.M. \& Kalff J. (1987) Latitudinal influences on depths of maximum colonization and maximum biomass of submerged angiosperms in lakes. Canadian Journal of Fisheries and Aquatic Sciences, 44, 1759-1764.

de Eyto E., Irvine K., García-Criado F. et al. (2003) The distribution of chydorids (Branchiopoda, Anomopoda) in European shallow lakes and its application to ecological quality monitoring. Archiv für Hydrobiologie, 156, 181-202.

Fernando C.H. (1994) Zooplankton, fish and fisheries in tropical freshwaters. Hydrobiologia, 272, 105-123. 
Flössner D. (2000) Die Haplopoda und Cladocera Mitteleuropas. Backhuys Publishers, Leiden, The Netherlands.

Frey D.G. (1959) The taxonomic and phylogenetic significance of headpores of the Chydoridae Cladocera. Internationale Revue der Gesamten Hydrobiologie, 44, 27-50.

Goncalves A.M.M., Castro B.B., Pardal M.A. \& Goncalves F. (2007) Salinity effects on survival and life history of two freshwater cladocerans (Daphnia magna and Daphnia longispina). Annales De Limnologie-International Journal of Limnology, 43, 13-20.

Gyllström M., Hansson L.A., Jeppesen E. et al. (2005) The role of climate in shaping zooplankton communities of shallow lakes. Limnology and Oceanography, 50, 20082021.

Hill M.O. (1973) Diversity and evenness: a unifying notion and its consequences. Ecology, 54, 427-432.

Hillebrand H. (2004) On the generality of the latitudinal diversity gradient. American Naturalist, 163, 192-211.

Hobæk A., Manca M. \& Andersen T. (2002) Factors influencing species richness in lacustrine zooplankton. Acta Oecologica, 23, 155-163.

IPCC (2007) http://ipcc-wg1.ucar.edu/wg1/docs / WG1AR4_SPM_Approved_05Feb.pdf.

Jakobsen T.S., Hansen P.B., Jeppesen E., Grønkjær P. \& Søndergaard M. (2003) Impact of three-spined stickleback Gasterosteus aculeatus on zooplankton and chl $a$ in shallow, eutrophic, brackish lakes. Marine Ecological Progress Series, 262, 277-284.

Jeppesen E., Madsen E.A. \& Jensen J.P. (1996) Reconstructing past density of planktivorous fish and trophic structure from sedimentary zooplankton fossils: a surface sediment calibration data set from shallow lakes. Freshwater Biology, 36, 115-127.

Jeppesen E., Jensen J.P., Amsinck S.L., Landkildehus F., Lauridsen T. \& Mitchell S.F. (2002) Reconstructing the historical changes in Daphnia mean size and planktivorous fish abundance in lakes from the size of Daphnia ephippia in the sediment. Journal of Paleolimnology, 27, 133-143.

Jeppesen E., Jensen J.P., Lauridsen T., Amsinck S.L., Christoffersen K., Søndergaard M. \& Mitchell S.F. (2003) Sub-fossils of the cladocerans in the surface sediment of 135 lakes as proxies for community structure of zooplankton, fish abundance and lake temperature. Hydrobiologia, 491, 321-330.

Jeppesen E., Søndergaard M., Mazzeo N., Meerhoff M., Branco C., Huszar V. \& Scasso F. (2005) Lake restoration and biomanipulation in temperate lakes: relevance for subtropical and tropical lakes. In: Tropical Eutrophic Lakes: Their Restoration and Management (Ed. M.V. Reddy), pp. 331-359. Science Publishers Inc., New York, U.S.A.
Jeppesen E., Meerhoff M., Jakobsen B.A., Hansen R.S., Søndergaard M., Jensen J.P., Lauridsen T.L., Mazzeo N. \& Branco C. (2007) Restoration of shallow lakes by nutrient control and biomanipulation - the successful strategy varies with lake size and climate. Hydrobiologia, 581, 269-285.

Korhola A. (1999) Distribution patterns of Cladocera in subarctic Fennoscandian lakes and their potential in environmental reconstruction. Ecography, 22, 357373.

Korhola A., Sorvari S., Rautio M., Appleby P.G., Dearing J.A., Hu Y., Rose N., Lami A. \& Cameron N.G. (2002) A multi-proxy analysis of climate impacts on the recent development of subarctic Lake Saanajarvi in Finnish Lapland. Journal of Paleolimnology, 28, 59-77.

Leavitt P.R., Sanford P.R., Carpenter S.R. \& Kitchell J.F. (1994) An annual fossil record of production, planktivory and piscivory during whole-lake manipulations. Journal of Paleolimnology, 11, 133-149.

Legendre P. \& Legendre L. (1998) Developments in Environmental Modelling, 2nd edn. Elsevier, Amsterdam.

Lepš J. \& Šmilauer P. (2003) Multivariate Analysis of Ecological Data Using CANOCO. Cambridge University Press, Cambridge.

Liboriussen L. \& Jeppesen E. (2003) Temporal dynamics in epipelic, pelagic and epiphytic algal production in a clear and a turbid shallow lake. Freshwater Biology, 48, 418-431.

Lotter A.F., Birks H.J.B., Hofmann W. \& Marchetto A. (1997) Modern diatom, cladocera, chironomid, and chrysophyte cyst assemblages as quantitative indicators for the reconstruction of past environmental conditions in the Alps. 1 Climate. Journal of Paleolimnology, 18, 395-420.

Manca M., Torretta B., Comoli P., Amsinck S.L. \& Jeppesen E. (2007) Major changes in trophic dynamics in large, deep sup-alpine Lake Maggiore from 1940s to 2002: a high resolution comparative palaeo-neolimnological study. Freshwater Biology, 52, 2256-2269.

Meerhoff M., Iglesias C., Teixeira De Mello F., Clemente J.M., Jensen E., Lauridsen T.L. \& Jeppesen E. (2007a) Effects of habitat complexity on community structure and predator avoidance behaviour of littoral zooplankton in temperate versus subtropical shallow lakes. Freshwater Biology, 52, 1009-1021.

Meerhoff M., Clemente J.M., Teixeira de Mello F., Iglesias C., Pedersen A.R. \& Jeppesen E. (2007b) Can warm climate-related structure of littoral predator assemblies weaken clear water state in shallow lakes? Global Change Biology, 13, 1888-1897. 
Mittelbach G.G., Schemske D.W., Cornell H.V. et al. (2007) Evolution and the latitudinal diversity gradient: speciation, extinction and biogeography. Ecology Letters, 10, 315-331.

Moss B., Stephen D., Alvarez C. et al. (2003) The determination of ecological status in shallow lakes a tested system (ECOFRAME) for implementation of the European Water Framework Directive. Aquatic Conservation: Marine and Freshwater Ecosystems, 13, 507549.

New M., Humble M. \& Jones P.D. (2000) Global 30-year Mean Monthly Climatology, 1961-1990 (Internet). Oak Ridge National Laboratory Distributed Archive Center, Oak Ridge, Tennessee. Data set available from http://www.daac.ornl.gov. Accessed May 2007.

Nõges P., Nõges T., Tuvikene L. et al. (2003) Factors controlling hydrochemical and trophic state variables in 86 shallow lakes in Europe. Hydrobiologia, 506, 51-58.

Ortega-Mayagoitia E., Armengol X. \& Rojo C. (2000) Structure and dynamics of zooplankton in a semi-arid wetland, the national park Las Tablas De Daimiel (Spain). Wetlands, 20, 629-638.

Røen U.I. (1995) Gxllefødder og karpelus. Danmarks Fauna 85. Dansk Naturhistorisk Forening, Vinderup Bogtrykkeri A7S, Vinderup, Denmark.

Romo S., Miracle M.R., Vellena M., Rueda J., Ferriol C. \& Vicente E. (2004) Mesocosm experiments on nutrient and fish effects on shallow lake food webs in a Mediterranean climate. Freshwater Biology, 49, 15931607.

Rooney N. \& Kalff J. (2000) Inter-annual variation in submerged macrophyte community biomass and distribution: the influence of temperature and lake morphometry. Aquatic Botany, 68, 321-335.

Sarmaja-Korjonen K. (2004) Chydorid ephippia as indicators of past environmental changes - a new method. Hydrobiologia, 526, 129-136.
Smol J.P., Wolfe A.P., Birks H.J.B. et al. (2005) Climatedriven regime shifts in the biological communities of arctic lakes. Proceedings of the National Academy of Sciences of the United States of America, 102, 4397-4402.

Sokal R.R. \& Rohlf F.J. (1981) Biometry. The Principles and Practice of Statistics in Biological Research, 2nd edn. W.H. Freeman and Company, New York.

Teixeira-de Mello F., Meerhoff M., Pekcan-Hekim Z. \& Jeppesen E. (2009) Littoral fish community structure and dynamics differ substantially in shallow lakes under contrasting climates. Freshwater Biology, 54, 1202-1215.

Vadeboncoeur Y., Jeppesen E., Vander Zanden M.J., Schierup H.H., Christoffersen K. \& Lodge D.M. (2003) From Greenland to green lakes: cultural eutrophication and the loss of benthic pathways in lakes. Limnology and Oceanography, 48, 1408-1418.

Vandekerkhove J., Declerck S., Jeppesen E., CondePorcuna J.M., Brendonck L. \& De Meester L. (2005a) Dormant progagule banks integrate spatio-temporal heterogeneity in cladoceran communities. Oecologia, 142, 109-116.

Vandekerkhove J., Declerck S., Brendonck L., CondePorcuna J.M., Jeppesen E., Sander Johansson L. \& De Meester L. (2005b) Uncovering hidden species: hatching diapausing eggs for the analysis of cladoceran species richness. Limnology and Oceanography: Methods, 3, 399407.

Verschuren D. \& Marnell M. (1997) Fossil Zooplankton and the Historical Status of Westslope Cutthroat Trout in a Headwater Lake of Glacier National Park, Montana. Transactions of the American Fisheries Society, 126, 21-34.

Verschuren D., Tirby J., Sabbe K. \& Roberts N. (2000) Effects of depth, salinity and substrate on the invertebrate community of a fluctuating tropical lake. Ecology, 81, 164-182.

(Manuscript accepted 11 May 2009) 